\title{
Anton Ghon and His Colleagues and Their Studies of the Primary Focus and Complex of Tuberculosis Infection and Their Relevance for the Twenty-First Century
}

\author{
Peter R. Donald ${ }^{a, b} \quad$ Andreas H. Diacon ${ }^{c}$ Stephanie Thee ${ }^{d}$ \\ aDepartment of Paediatrics and Child Health, Desmond Tutu TB Centre, Faculty of Medicine and Health Sciences,

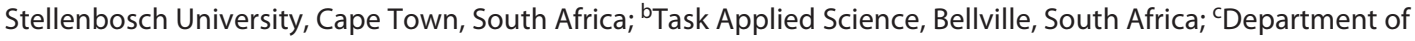 \\ Medicine, Faculty of Medicine and Health Sciences, Stellenbosch University, Cape Town, South Africa; ${ }^{\mathrm{d} D e p a r t m e n t}$ \\ of Pediatrics, Division of Pneumonology and Immunology with Intensive Medicine, Charité Universitätsmedizin, \\ Berlin, Germany
}

\begin{abstract}
Anton Ghon is well known in the field of childhood tuberculosis, and the tuberculosis primary focus and complex are frequently called the Ghon focus and complex; this is largely the result of the wide publication of the English translation of his monograph “Der primäre Lungenherd bei der Tuberkulose der Kinder." Ghon's studies are frequently quoted, but precise details of his monograph are neglected, his results often misquoted, and his later publications virtually unknown. This review highlights aspects of Ghon's anatomical pathology studies in children and adults not necessarily dying of tuberculosis but with signs of tuberculosis infection. Ghon found a single primary tuberculosis focus in approximately $80 \%$ of tuberculosis-infected children situated close to the pleura in two-thirds of cases. Cavitation of the focus was common, and lymphatic spread involved lymph nodes in the abdomen and neck in many children. Studies amongst adults and children frequently found the healed primary tuberculosis focus to be completely calcified without histological signs of tuberculosis activity; however, particularly in the presence of pulmonary tuberculosis, histological signs of tuberculosis activity were often found in the lymph nodes of the angulus venosus, despite apparent healing with extensive calcification. Both earlier studies and
\end{abstract}

more recent investigations, with molecular biological tools, unavailable to Ghon and earlier researchers, have confirmed the presence of viable mycobacteria in apparently normal or healed thoracic nodes and also found molecular biological indications of viable mycobacteria in these nodes. As suggested by Ghon, lympho-haematogenous spread of tuberculosis may be more common than is usually appreciated.

(c) 2020 S. Karger AG, Basel

\section{Introduction}

Anton Ghon (Fig. 1) is well known in the field of childhood tuberculosis (TB), and this is largely the result of his much-quoted monograph "Der primäre Lungenherd bei der Tuberkulose der Kinder" published in German in 1912 [1] and subsequently published in English in 1916 as "The Primary Lung Focus of Tuberculosis in Children" [2]. This latter publication ensconced Ghon's name in the

From the Thematic Review Series: "Tuberculosis" Series Editors: Coenraad F. Koegelenberg, Christoph Lange, Otto D. Schoch. 


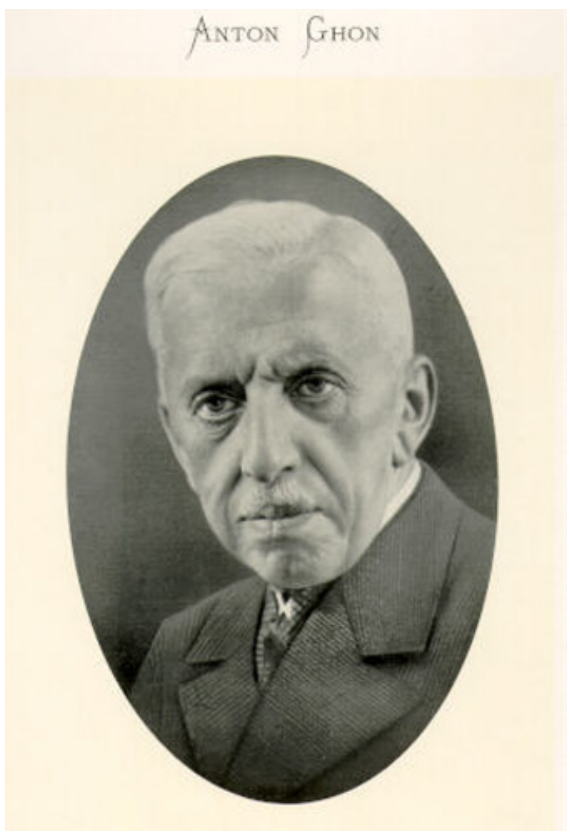

Fig. 1. A signed photograph of Anton Ghon that appears in the Vitalis Gallery of prominent natural science and medical researchers.

childhood TB literature. Although Ghon's name is firmly linked to the TB primary focus and complex, he was part of a large body of researchers, whose findings preceded and followed Ghon's monograph and helped underpin his conclusions. Ghon's studies are often quoted, but the precise details of his monograph are neglected, his results often misquoted, and his later publications virtually unknown. In this article, we review Ghon's monograph, his later publications, and those of his contemporaries and their relevance today.

\section{Methodology}

We searched PubMed using Ghon's name and the words tuberculosis, primary focus, and complex. Older text books in English and German were sourced and searched for references related to early anatomical pathology studies of the TB primary infection focus and complex, and these articles were further reviewed.

\section{Context}

René Laennec unified the concept of TB demonstrating that the tubercle was the basic feature of TB and was present in all TB lesions; it was the same disease that was responsible wherever tubercles were identified [3]. Laennec noted the presence of TB thoracic lymph nodes in children, but often failed to find pulmonary lesions, concluding that ulcerating mediastinal nodes spread TB into the pulmonary tissues.

The first firm indication of the true features of primary TB infection in children and an indication of the likely route of TB infection were provided by Joseph Marie Jules Parrot. In 1876, Parrot, working in Paris, presented his findings following 145 post-mortem examinations of children aged 1-7 years to the Société de Biologie [4]. Whenever there was a TB lesion in the bronchial lymph nodes, a similar lesion was present in the lungs; this might be very small and difficult to locate. Parrot described the mediastinal lymph nodes as the mirror of the lungs. Parrot's pupils and successors Hervouët [5] and Hutinel continued his studies, and George Küss's thesis "De l'hérédité parasitaire de la tuberculose humaine," published in 1898, guided by Hutinel, placed the matter beyond reasonable doubt, clearly demonstrating the relationship between TB-infected mediastinal nodes and the pulmonary TB focus. TB was an aerogenous infection and not the consequence of congenital infection lurking in the mediastinal lymph nodes or an abdominal infection [6].

Despite Küss's findings, early pathologists continued reporting prominent bronchial and paratracheal nodes in children with TB but still seldom identified a pulmonary focus [7-9]. However, Eugen Albrecht in Munich in 1907 [10] and Heinrich Albrecht in 1909 [11], a Vienna colleague of Ghon, reported findings similar to those of their French colleagues, as did Hedren in 1912 in Stockholm [12].

Heinrich Albrecht's results are noteworthy; between 1903 and 1909, he carried out post-mortem examinations on 1,060 children with signs of TB infection; 191 (14.6\%) were infants, 691 (44.3\%) aged 1-6 years, and 178 (50.1\%) aged 6-12 years. TB was the cause of death in only a proportion of children; the commonest causes of death being inter-current infectious diseases such as measles, diphtheria, scarlet fever, and pneumonia [11]. The foci could be very small, especially when healed, and he often localized them by noting the situation of the mediastinal nodes and carefully massaging the lungs in a distal direction. He considered the consistent relationship of the focus and lymph nodes to have the features of a law governing events. Albrecht also emphasized the manner in which TB spread via the lymph circulation in different directions.

Thus, when Ghon commenced his studies, the broad outlines of the path of TB infection were clear, even if not widely accepted, and still vigorously contested by leading researchers such as Calmette and Guérin in France and von Behring and Schlossmann in Germany [13-15]. 
Table 1. Main anatomical pathology features found during Anton Ghon's post-mortem studies of primary childhood TB during the period 1907-1909 at St Anna Children's Hospital, Vienna [2]

\begin{tabular}{|c|c|c|}
\hline \multirow{2}{*}{$\begin{array}{l}\text { Post- } \\
\text { mortems, } \\
n\end{array}$} & \multicolumn{2}{|c|}{$\begin{array}{l}\text { Causes of death as result of TB, } \\
n(\%)\end{array}$} \\
\hline & TBM & $\begin{array}{ll}\text { general or } & \text { other } \\
\text { miliary TB } & \text { TB }\end{array}$ \\
\hline
\end{tabular}

Primary focus outside the lungs

No recognizable primary focus, but TST positive ${ }^{\mathrm{a}}$

$\mathrm{TB}$ of nodes adjoining the lungs, but no lung focus found

TB nodes adjoining the lungs but also TB of other organs and their tributary nodes that might have been a channel of entry

Total

5

2

3

4

14

Cases with a primary lung focus

I. A lung focus without any nodal TB detected

II. A lung focus with lung lymph node involvement

III. A lung focus with nodal TB involvement and haematogenous spread to other organs

IV. As above, but now with lymph node involvement related to other organs that might be a channel of TB infection

V. As in IV, but with recent TB involvement of organs that might be a channel of infection

VI. As above, but with older TB changes although not as old as those of the pulmonary focus

VII. A focus present in both the lungs and organs outside the lungs that could possibly be a primary entry point

Total

184

\begin{tabular}{rcrl}
1 & - & & \\
34 & \multicolumn{1}{l}{ - } & & \\
20 & $13(65)$ & & $3(15)$ \\
& & & \\
25 & $13(52)$ & $7(28.0)$ & $\mathrm{I}(4)$ \\
64 & $30(46.9)$ & $23(35.9)$ & $2(3.1)$ \\
11 & $4(36.4)$ & $5(45.5)$ & \\
15 & $2(13.3)$ & $5(33.3)$ & $2(13.3)$ \\
& & & \\
184 & $62(33.7)$ & $40(21.7)$ & $8(4.3)$
\end{tabular}

TB, tuberculosis; TST, tuberculin skin test; TBM, tuberculous meningitis. ${ }^{\text {a }}$ In 1 case, a positive guinea pig culture of $M$. tuberculosis was obtained from a macroscopically normal lymph node.

\section{A Brief Outline of Anton Ghon's Career}

Anton Ghon was born on January 1, 1866, in Villach, Austria, attended university in Graz, graduated in 1890, and became an assistant to Weichselbaum in the Institute for Pathological Anatomy in Vienna and investigated meningococcal infections. Later, he studied bubonic plague in Bombay with Heinrich Albrecht and in 1902 became professor extraordinarius in Vienna and assistant in the Patho-Anatomical Institute of St Anna Children's Hospital, one of the foremost European paediatric centres. In 1910, he accepted the Chair of Pathological Anatomy at the German University in Prague and continued publishing actively, assisting his younger colleagues until his retirement in 1935 . He was twice elected dean of the Prague faculty and once rector [16].

Ghon's career developed in the aftermath of Robert Koch's discovery of Mycobacterium tuberculosis as the cause of TB, and he was fortunate to commence his studies at St Anna Children's Hospital where Theodore Escherich was the head. Escherich initiated a number of original infectious disease studies and was amongst the first to explore the use of radiology in children and played an important role in the development of paediatrics and paediatric infectious diseases as specialities. He also instituted the routine tuberculin skin testing of every child admitted to the St Anna Hospital [17].

\section{Anton Ghon's Studies of the Route and Consequences of Primary TB Infection}

In the introduction to his monograph, Ghon first pays tribute to his colleagues and predecessors. He notes that in 1903, Escherich drew his attention to Küss's work and admits that his investigations do not report anything new, but hopes that "wider recognition of the primary lung focus of tuberculosis in childhood" will result and that he can "enlarge on the results we have hitherto had at our disposal." He thus began with a considerable advantage; he knew what he was looking for!

The materials Ghon drew upon originated during the years 1902-1910, but between 1903 and 1907, he states that he was developing his techniques, "working as uniformly as possible," but still dissatisfied with his skill and insights. Nonetheless, his Vienna colleagues Hamburger and Sluka used his post-mortem findings in a 1904 paper [9]. 
The cases recorded in his monograph date from the years 1907 to 1909 during which Ghon performed 644 post-mortem examinations; amongst these, 184 (28.6\%) were on children with documented TB changes. These children were aged from infancy to completion of their 14 th year and included a high proportion of infants (27.2\%) due to the admission policy of St Anna Hospital; $16.3 \%$ were in their second year of life; the ages of the remainder ranged from 3 to 14 years.

The extent of TB disease and the nature of the changes found on post-mortem examination are summarized in Table 1. Ghon arranged the individual cases into 7 divisions reflecting the extent of the spread of infection, either lymphogenous, haematogenous, or following "canalicular" aspiration via the bronchi and gastrointestinal tract.

Overall, there were 14 (7.6\%) children with no lung focus detected. Seven presented with mediastinal TB nodal disease, but no lung focus was found; 2 (1.1\%) children showed positive tuberculin skin testing without any other detectable TB signs, and in one of these, the contents of several macroscopically normal tracheobronchial nodes produced a positive culture of M. tuberculosis in a guinea pig. Five $(2.7 \%)$ children had an extra-pulmonary primary TB infection. These foci were in a tonsil, the jejenum, and the small intestine, while a tuberculous retro-auricular lymph node and mesenteric lymph nodes indicated 2 other probable infection sites. In another 4 $(2.2 \%)$ cases, there were tuberculous lymphatic glands adjoining the lungs but also tuberculous changes in other organs.

In a further 15 cases, a lung focus of infection was detected, but organs other than the lungs came into contention as possible channels of infection, and it was impossible to decide which was the primary focus; the possibility of a simultaneous entry point at both sites was conceded. Ghon cautions that the results are mainly based on anatomical and macroscopic findings.

\section{$T B$ as the Cause of Death in the Children Studied}

The causes of death as a result of TB amongst the children studied are summarized in Table 1. TB caused death in $110(59.8 \%)$ of the 184 children with a primary TB; in $62(33.7 \%)$, tuberculous meningitis was the cause of death; in 40 (21.7\%), it was designated as "general TB," and one assumes this indicates miliary or haematogenous spread. Eight (4.3\%) children died as a result of other forms of TB including 2 cases each of abdominal TB and extensive caseating pneumonia, one each following spinal $\mathrm{TB}$, renal $\mathrm{TB}, \mathrm{TB}$ pericarditis, and compression of the right main bronchus.

\section{The Number of Lung Foci}

Although it is often stated that there is only 1 primary focus, in a minority of cases there may be more. In Ghon's series of 170 cases of primary pulmonary $\mathrm{TB}$, there was a single focus in $123(72.4 \%)$ cases; in $25(14.7 \%)$, there were 2 , in $11(6.5 \%)$ cases, 3 , in $5(2.4 \%)$ cases, 4 , and 5 or more in the remaining $6(3.5 \%)$.

Ghon is at pains to emphasize that these figures are an approximation. If the relevant lesions were close together, it was difficult to decide whether there really was $>1$ primary focus. He concedes the possibility of recent reinfection or the simultaneous deposit of another infectious particle. In a later 1923 paper, Ghon and Winternitz [18] described their findings in Prague on post-mortem examination of a further 551 children with pulmonary primary TB; 517 (93.8\%) had a single pulmonary primary focus. A similar predominance of single primary foci was noted by other researchers such as Hedren in Stockholm [12], Canti in London [19], Blumenberg in Magdeburg [20], Blacklock in Glasgow [21], and MacGregor in Edinburgh [22].

\section{Appearance and Size of the Lung Focus and the Presence of Cavitation}

The size of the foci was assessed using a rough "agricultural" classification, as was in practice in reports of this period. Amongst the 142 children with a single lung focus, $52(36.6 \%)$ had caseous changes. Of these, 16 (30.8\%) were considered to have foci the size of a pea, $9(17.3 \%)$ the size of a cherry, and $12(23.1 \%)$ the size of a hazel nut with intermediate gradations amongst the remainder. In 51 (35.9\%) children, cavitation was present, and the focus was considered the size of a pea in $9(17.6 \%)$, the size of a cherry in $6(11.8 \%)$, a hazel nut in $12(23.5 \%)$, and a nut in $11(21.6 \%)$. Amongst 34 older children with calcification or petrification of the focus, the foci tended to be smaller, and $22(64.7 \%)$ were the size of a pea or less. The size of the foci tended to be larger in the younger children, and size was associated with the degree of activity in a focus, which also tended to be more extensive in younger children.

Of the 52 foci with caseous changes, 21 (40.4\%) were surrounded by numerous tubercles that appeared to be dependent on the focus. These secondary foci were more prominent in cases with softening of the focus contents. Notably, in 15 (29\%) of 51 cases with a single lung focus and a cavity, there were surrounding tubercles.

In later studies drawing on material collected in Prague and Vienna, Ghon again reported the frequent presence of cavitation in the primary foci that was more common 

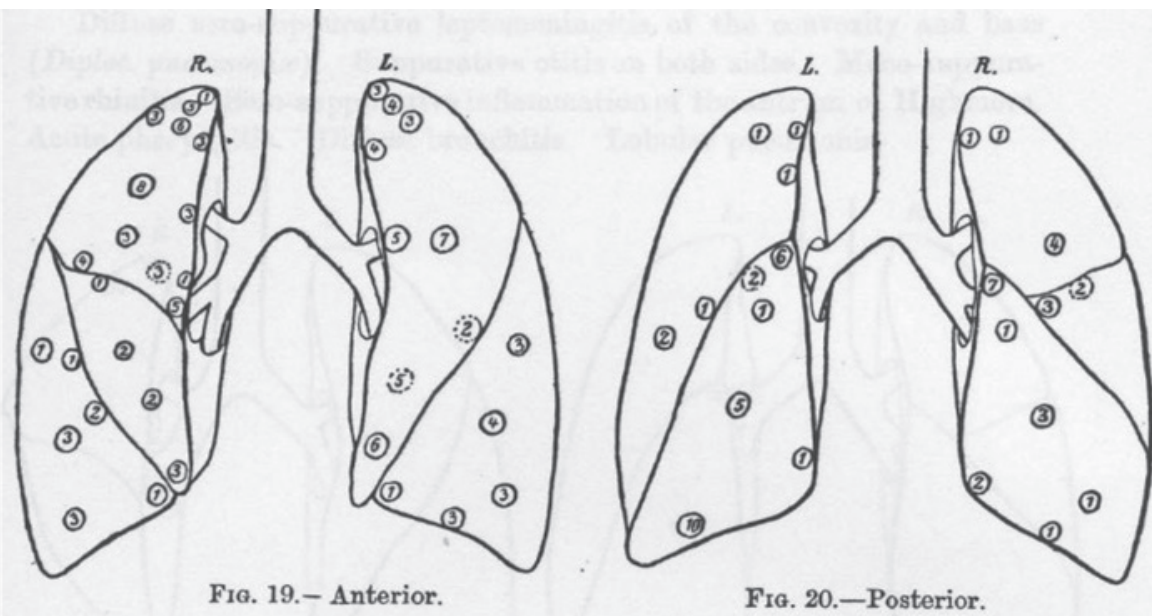

Fig. 2. Distribution of primary foci found during Anton Ghon's studies of primary TB in children in Vienna. "...practically all the sections showed lung foci, but ...generally speaking, the anterior upper portions of the upper lobes and the posterior lower portions of the lower lobes showed the greatest number..."[2]. TB, tuberculosis.

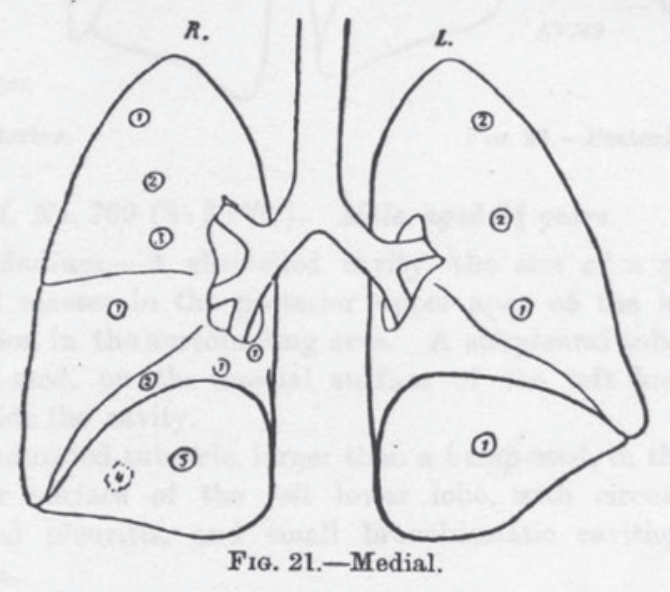

in younger children [23]. Amongst this joint group were 203 infants of whom 191 (94.1\%) had primary pulmonary TB; of these, 65 (34\%) had a cavity, or in 24 (12.6\%), caseous softening that was likely to proceed to cavitation; 81 (91\%) of these infants with cavitation or caseous softening had miliary TB, and amongst these, 24 (29.6\%) died of tuberculous meningitis.

Other pathologists also recorded frequent cavitation in the primary focus in children. Hedren described cavitation in $15(31.9 \%)$ of 47 cases $<1$ year of age and 30 (19.7\%) of $152>1$ year of age [12], Blumenberg in 30-40\% of children [20], and Blacklock in $52(30.6 \%)$ of 170 primary foci [21].

In 34 (23.9\%) of the Vienna children with a single lung focus, calcification or petrification of the focus was detected. These foci could be very small and easily overlooked.

\section{The Position of the Primary Focus and Pleural} Involvement

Ghon goes into considerable detail regarding the position of foci within different lobes and concedes that his localization is mainly macroscopic but considers this as fairly accurate. Figure 2 illustrates the position of the 142 single foci studied in Vienna [1]; Table 2 summarizes their positions together with the positions of the foci in a further 485 children, also with single primary foci studied later in Prague [18].

The right lung contained more foci than the left, and there were slightly more foci in the upper lobes than the lower lobes. Ghon points out that this finding differs from that of Küss who found more foci in the lower lobes but adds that the numbers in both studies are insufficient to reach any final conclusion. Regarding the position of all the foci within each lobe, Ghon provides a detailed analysis of the overall positions of the foci "the positions of which were determinable" within the different lobes (Ta- 
Table 2. Lobar disposition of single lung foci found during Anthon Ghon's post-mortem studies of primary childhood TB (A) during the period 1907-1909 at St Anna Children's Hospital, Vienna [1], and (B) during the period 1910-1923 at the Anatomical Pathology Institute in Prague [18]

\begin{tabular}{lccc}
\hline Lobe & Right lung & Left lung & Both lungs \\
\hline A & $44(50.6 \%)$ & $33(60 \%)$ & $77(54.2 \%)$ \\
Upper & $11(12.6 \%)$ & - & $11(7.8 \%)$ \\
Middle & $32(36.8 \%)$ & $22(40 \%)$ & $54(38.0 \%)$ \\
Lower & $87(61.3 \%)$ & $55(38.7 \%)$ & 142 \\
\hline Total & $139(52.9 \%)$ & $117(57.9 \%)$ & $256(555.1 \%)$ \\
\hline B & $37(7.6 \%)$ & $85(42.1 \%)$ & $172(37.0 \%)$ \\
Upper & $87(17.9 \%)$ & $850)$ \\
Middle & $263(56.5 \%)$ & $202(43.4 \%)$ & 465 \\
\hline Tower & & & \\
\hline
\end{tabular}

TB, tuberculosis.

ble 3). Nearly all subdivisions of the lungs and lobes had foci, but the anterior portions of the upper lobes and the posterior lower portions of the lower lobes contained a greater proportion. Regarding the right middle lobe, the upper and lower and anterior and posterior sections were equally affected. The lobar apices were affected, but only a minority of foci were found immediately beneath the apices.

In a later paper, Ghon provided a further detailed analysis of another 100 children with primary TB subject to post-mortem examination between 1911 and 1924. He divided each lung lobe into thirds and found the upper, middle, and lower thirds of all 5 lobes to be the site of a single primary focus in 37,33 , and $30 \%$ of cases [24].

In another similar analysis, Blacklock found 90 (53\%) of 170 single foci in the upper lobes with the majority in the upper two-thirds of the anterior surface of the right upper lobe and the middle third of the left upper lobe, but in the lower lobes, a majority were at the lower third of the posterior surface; the apices were also seldom affected [21]. Of 85 primary foci recorded by MacGregor working in Edinburgh, 37 (43.5\%) were in the right upper lobe and a further $8(9.4 \%)$ in the left upper lobe [22].

Amongst the 142 cases with a single lung focus included in Ghon's monograph, changes in the pleura were present in 95 (66.9\%); this varied from circumscribed adhesive pleuritis to pleuritis encompassing most of the lung where the focus was situated. In 5 instances, the pleuritis extend-
Table 3. Position of all the lung foci "whose positions ... were determinable" within the different lobes of the lungs found during Anthon Ghon's post-mortem studies of primary childhood TB during the period 1907-1909 at St Anna Children's Hospital, Vienna [1]

\begin{tabular}{lc}
\hline Position of all the foci within all the lobes $^{\mathrm{a}}$ & $N(\%)$ \\
\hline At the apices of the lobes & $38(19)$ \\
Immediately beneath the apex & $9(4.5)$ \\
At the borders & $43(21.5)$ \\
On the anterior surface & $51(25.5)$ \\
On the posterior surface & $19(9.5)$ \\
On the medial surface & $16(8.0)$ \\
On the basal and interlobular surface & $12(6.0)$ \\
\hline Total & 188 \\
\hline
\end{tabular}

TB, tuberculosis. ${ }^{\text {a }}$ The term apices in the first row includes, for example, the lower part of the anterior apex of the left upper lobes and thus would also include the apex of the lingula. ed over both lungs. Regarding all cases with a lung focus, pleural changes were present in 114 (67.1\%) of 170 cases. He also noted, particularly in cases with TB changes in the upper tracheobronchial nodes, that there were adhesions of nodes to the medial surface of the upper lobe pleura, this being particularly common on the right side. The subpleural localization of the primary foci was similarly reported by other pathologists $[12,20,21]$.

\section{Early Primary Foci}

In 1913, Zarfl described a primary focus in a 25-day-old infant [25], and in later studies, Ghon and his collaborators also described very early primary foci $[26,27]$, one of which was found in a child only 35 days old. Other descriptions of very early foci were provided by Blumenberg [20], Blacklock [21], and Pagel and Price [28]. The characteristic lesion seen, before the development of tuberculin positivity in several cases, was an exudative tuberculous broncho-pneumonia with some caseation centrally without tubercle development or any signs of fibrosis or capsule development but with abundant mycobacteria, the retention of some alveolar structures, and the presence of occasional epithelioid cells. In the cases reported by Zarffl and Pagel, no macroscopic changes were evident in any lymph nodes, but in the case of an infant only 35 days old reported by Ghon and Pototschnig, tuberculous changes were evident in some of the regional lymph nodes, and on microscopy, mycobacteria were seen [27]. 
In the closing paragraphs of his monograph, Ghon admits the possibility that infection of the lungs might result from ulceration of the mediastinal lymph nodes; however, this would usually follow after the primary infection has spread from the primary focus to the regional nodes and he states "...I have seen no case where the alterations in the lung focus showed a more recent stage of development of the tuberculous process, from a morbid anatomical standpoint than the alterations in the adjoining lymphatic glands." He concludes his monograph: “...in childhood the primary infection of the lungs represents the usual form of the tuberculous infection" [2].

\section{Endogenous and Exogenous TB Reinfection}

In a series of later papers, Ghon and his colleagues followed the extension of the primary complex via the mediastinal lymph vessels and lymph nodes to the angulus venosus at which point the lymph vessels discharge into the subclavian veins often via the ductus thoracicus and the ductus lymphaticus. With Ranke [29], he considered the TB changes a logical extension of the primary complex. He speculated that the lymph nodes in the angulus venosus might be a common portal of access for bacilli into the lungs during primary infection and for further haematogenous dissemination during the later development of endogenous TB reinfection after healing of the primary focus [30]. Case reports gave detailed descriptions of adults, adolescents, and children, who on post-mortem examination were found to have calcified, inactive primary foci from an earlier primary infection, either as a child or later as an adolescent or adult, but now had signs of "lympho-glandular reinfection" [31-33].

On post-mortem examination of 100 unselected cases of pulmonary $\mathrm{TB}$, their ages ranging from 1 to 70 years, Ghon and his colleagues $[34,35]$ paid particular attention to the lymph nodes of the angulus venosus, histologically evaluating the presence of fresh TB changes in these nodes and lymph vessels. In approximately $90 \%$ of cases investigated, changes identified in the angulus venosus lymph nodes were compatible with $\mathrm{TB}$, one sided in 26 cases, but bilateral in 63 . These changes varied, including the presence of tubercles with epithelioid giant cells, with or without caseation, older changes histologically definitely related to tubercles, hyalinized or calcified foci with giant cells and Langhans cells visible on the edges, and hyalinized or calcified foci with signs of previous TB on histology. Finally, in a minority of cases, reticulum thickening frequently accompanying $\mathrm{TB}$ was noted without any signs of active TB.

Ghon and His Colleagues and Primary

Focus and Complex of Tuberculosis
Nearly always the primary focus appeared healed and calcified, but on histological examination, there were frequently fresh tuberculous changes in the lymphogenous drainage region of the primary complex, and these changes often appeared even in the presence of extensive calcification of the lymph nodes and vessels. Ghon and his collaborators [34] speculated about the origin of what was known as reinfection TB and whether it was possible to separate exogenous and endogenous "reinfection." They pointed out that there were 2 "camps" vigorously advocating each possibility; Ghon likened exogenous reinfection to "superinfection"; this he contrasted with endogenous reinfection, which he considers is, perhaps, better termed "metastatic reinfection." Ghon appeared to favour the definitions of Orth according to which endogenous reinfection was every new infection with tubercle bacilli caused by the same organisms already present in the individual's body $[35,36]$. Orth considered that exogenous reinfection occurred when an already TB-infected individual sustained an infection with a tubercle bacillus that was not a direct descendant of the original infecting bacillus.

In this way, Ghon was drawn into the controversies surrounding the origins of apical TB lesions common in adolescents and adults and then known as phthisis, a contentious subject still relevant today $[37,38]$. He considered that the frequent, persistent occurrence of TB in the lymphatic drainage of the primary focus might lead to haematogenous infection of the lungs when the infected lymph was discharged into the vena cava blood vessels and that these changes might ultimately be responsible for a considerable proportion of haematogenous TB spread to the lungs and other organs.

\section{Discussion}

Although Anton Ghon's monograph and subsequent publications did not state anything new regarding the primary focus and complex of TB, as he himself acknowledged, he presented his data systematically and in detail so that it was very difficult for advocates of other routes of TB infection, notably gastrointestinal, to dispute his conclusions. Our review draws attention to the details of Ghon's studies of the primary focus and, in particular, the lymphatic component of the primary complex and its possible contribution to the establishment of the apical lung foci that are possibly responsible for the further spread of TB infection, particularly at some later point following the healing of the primary focus. 
It is often stated that the primary focus is situated in the bases of the lung lobes and more frequent in the lower lobes and this is contrasted with the frequent upper lobe, apical localization of the adult, or adolescent lesions $[39,40]$. The wide distribution of primary foci in Ghon's studies, with a slight predominance in the upper lobes, is well illustrated in Figure 2. Tables 1 and 2 show that there are more foci in the upper lobes, but that this difference is, again, not marked. Other researchers [20-22], with the exception of Küss [6], also reported a predominance of upper lobe primary foci in children. In contrast, during a study of minimal pulmonary TB lesions in adults, Medlar reported that two-thirds of calcified primary complexes in adults were found in the lower half of the lung fields. However, the calcified lesions reported in this study had to have a diameter of at least $2 \mathrm{~mm}$ and both the primary focus and the relevant nodes had to be calcified. It can be questioned whether these lesions give a true picture of the distribution of primary TB foci or were all actually the result of primary TB [41]. Secondary lesions arising from a cavitated primary focus might also calcify as might lesions arising from later reinfection $\mathrm{TB}$.

It is also often stated that the primary focus does not cavitate $[40,42]$, but a significant proportion of children, particularly younger children, studied by Ghon and other pathologists did have cavitary lesions and these, likely, can also occur in primary foci in adults following primary infection $[43,44]$. These lesions probably contribute to the finding of viable $M$. tuberculosis in gastric aspirates or sputum specimens from recently infected, but apparently normal children and adults [43-46]. As stated by Ghon's colleague Heinrich Albrecht, primary TB in children is a form of "open TB" that can spread via the bronchi to infect other organs, especially in the oropharynx and gastrointestinal tract [11].

During his post-mortem examinations, Ghon, and other early pathologists, paid particular attention to the lymph nodes and lymph vessels and documented a wide distribution of TB lesions, in both superior and inferior directions. Cervical or submandibular nodes might be involved, as might the nodes of the celiac plexus below the diaphragm. Heinrich Albrecht stated that he seldom found TB involvement of the cervical nodes, nor inferior spread of infection below the diaphragm involving the lymph nodes adjoining the abdominal organs, without initial involvement of the tracheobronchial nodes [11]. In his later papers, Ghon frequently returned to the response of the mediastinal lymph nodes and the lymphatic vasculature to TB infection, but emphasized, in particular, the potential role of the lymph nodes of the angulus venosus in the pathogenesis of apical cavitating lesions in adolescents and adults and endogenous reinfection. Despite calcification and the apparent complete resolution of TB activity in the primary focus, histological signs of fresh activity were frequently found in the thoracic lymph nodes [31-35].

In support of the histological findings of TB activity in the mediastinal lymph nodes during Ghon's studies, it is relevant to note that numerous later investigators documented the detection of viable $M$. tuberculosis in material obtained during post-mortem examinations or biopsy from mediastinal tuberculous lymph nodes, even in the presence of overt calcification [47-50]. While these findings usually represented only a minority of cases investigated, they confirm that what Ghon termed lymphogenous-endogenous reinfection is a decided possibility. Canetti [50], following an extensive series of postmortem examinations in adults carried out in Paris between 1940 and 1945, concluded that endogenous reinfection was most unlikely to be a cause pulmonary TB reinfection. Nonetheless, his own studies did report positive cultures of $M$. tuberculosis from calcified, apparently latent pulmonary or glandular foci in $11(25 \%)$ of 44 adults [50].

Both Ghon and Arnold Rich stated cogently that both endogenous and exogenous TB reinfection occur but that the frequency with which they occur under different circumstances was uncertain $[33,51]$. In any HIV high-incidence community, both endogenous reactivation and exogenous reinfection will likely continue to be important sources of pulmonary TB $[52,53]$. Against the above background, epidemiological data suggest that the relative importance of endogenous reinfection, whatever its source, will likely also be determined by the level of TB infection risk, the secular trend of this risk, and the age distribution of the relevant population. In the Netherlands, during the period 1951-1970, the risk of infection declined dramatically by almost $14 \%$ annually. During this period, the largest contributor to TB notifications in the male age group 15-19 years was primary infection. However, in the male age group 60-64 years, exogenous reinfection and endogenous reactivation became much more important, and as the annual risk of infection declined further, the role of endogenous reactivation increased in importance [54]. A similar epidemiological study using notification data from England and Wales for the period 1900-1990 also concluded that the risk of infection was the most important factor determining the origin of pulmonary TB cases. As the occurrence of primary infection and exogenous infection declined, the 
proportion of TB cases ascribed to endogenous reactivation became more important [55].

Much more recently, investigations such as positron emission tomography with concurrent computerized tomography that is able to detect, locate, and quantify neoplastic and inflammatory activity with increasing accuracy have been used to study metabolic activity in the mediastinal lymph nodes in individuals with probable persistent TB infection and have demonstrated activity in suspicious circumstances [56-58]. Other investigators using real-time polymerase chain reaction and immunochemistry have documented the presence of considerable amounts of $M$. tuberculosis constituents in these calcified lymph node lesions [59].

Lymph nodes are not only sites of antigen presentation and immune activation during infection but might also serve as important sites for persistence of significant numbers of $M$. tuberculosis bacilli [60]. From the evidence available, it appears that lymph nodes represent a plausible anatomical reservoir and macrophages a plausible cellular niche for bacterial persistence, the latter also providing $M$. tuberculosis bacilli with the necessary mobility to escape the reservoir and enter the blood stream to cause secondary, active TB disease. In support of Ghon's theories, we see more and more indirect evidence that TB may persist in and spread via lymph nodes, and that the angulus venosus might indeed represent a stepping stone for macrophages carrying $M$. $t u$ berculosis to enter the systemic circulation. Furthermore, several recent publications have again emphasized the role of the lymphatic system in the pathogenesis of TB [61], and it is suggested that TB could be considered a lymphatic disease [62]. Equally important is the role of specialized macrophages in the transport of bacilli via the lymphatic circulation to the regional lymph nodes that are better able to induce a protective immunological response $[63,64]$. Despite the important role of the macrophages in controlling TB, they might also offer a means of transport for the otherwise inert $M$. tuberculosis. Might TB not also be considered a macrophage disease, needing the lymphatic system and the macrophage for transport, thus enabling the bacilli to reach the blood circulation via the angulus venosus and to access the lungs from where the circle of infection might be completed [37, 64].

Wide-ranging spread of TB via the lymphatic system following primary TB infection was demonstrated by early pathologists, and peripheral TB lymphadenopathy remains a common manner of presentation of primary $\mathrm{TB}$ [65]. Would TB be able to spread as widely in the body as it frequently does without the aid of the lymph nodes, the lymphatic vasculature, and the macrophages, Robert Koch's "Wanderzelle"? [66].

In conclusion, not only did Anton Ghon make a major contribution to our understanding of primary TB and its anatomical pathology, but he also made a significant, previously unacknowledged contribution to our knowledge of the effects of primary TB infection regarding the lymph nodes and the lymphatic vasculature and their role in the pathogenesis of TB. On a final note of irony, Anton Ghon died on April 23, 1936, of tuberculous pericarditis.

\section{Acknowledgements}

The authors thank the librarians of the library of the Faculty Medicine and Health Sciences, Stellenbosch University, South Africa, in particular, Mrs. Tracey Louw, and the librarians of Charité University Hospital, Berlin, Germany, who were most helpful in retrieving the older literature regarding the life and research activities of Anton Ghon and his colleagues.

\section{Conflict of Interest Statement}

None of the authors have any possible conflicts of interest or have received any financial support that could influence the contents of this review.

\section{Funding Sources}

No financial support was received by any of the authors for the conduct or writing of this historical review.

\section{Author Contributions}

This historical review was conceived by P.R.D. and discussed and agreed with S.T. and A.H.D. All the authors contributed to the acquisition of the necessary references, the review of the references, the interpretation of the findings, and the selection of the data to include in the review. The first draft of the paper was written by P.R.D. and reviewed and amended by S.T. and A.H.D. All the authors have agreed to the final version of the review.

\section{References}

1 Ghon A. Der primäre lungenherd bei der tuberkulose der kinder. Berlin-Wien: Urban \& Schwarzenberg; 1912.

2 Ghon A. The primary lung focus of tuberculosis in children. New York: Paul B. Hoeber; 1916.

3 Sakula A. R T H Laennec 1781-1826 his life and work: a bicentenary appreciation. Thorax. 1981;36:81-90.
Ghon and His Colleagues and Primary

Focus and Complex of Tuberculosis 
4 Parrot JMJ. Comp Rend Soc Biol. 1876;28: 308-9.

5 Hervouët $\mathrm{H}$. Adénopathies similaires chez l'enfant. Thèses $p 1$ doctorat en Méd. Paris; 1877.

6 Küss G. De l'hérédité parasitaire de la tuberculose humaine. Paris: Asselin et Houzeau; 1898.

7 Birch-Hirschfeld FV. Über den Sitz und die Entwicklung der primären Lungentuberkulose. Dtsch Arch Klin Med. 1899;64:58.

8 Naegeli O. Ueber Häufigkeit, Localisation und Ausheilung der Tuberculose. Arch Pathol Anat. 1900;160(2):426-72.

9 Hamburger F, Sluka E. Beitrag zur Kenntnis der Tuberkulose im Kindesalter. Jahrb Kinderheilkd Phys Erzieh. 1904;62:517-46.

10 Albrecht E. Thesen zur Frage der menschlichen Tuberkulose. Frankf Z Patol. 1907;1:214-20.

11 Albrecht H. Über Tuberkulose des Kindesalters. Wien Klin Wochenschr. 1909;22:327-34.

12 Hedren G. Pathologische Anatomie und Infektionsweise der Tuberkulose der Kinder, besonders der Säuglinge. Z Hyg Infektionskrankh. 1912;73:273-323.

13 Calmette A, Guérin C. Origine intestinale de la tuberculose pulmonaire Ann de L'Inst Pasteur. Paris; 1905. Vol. xix; p. 601.

14 von Behring E. Tuberkuloseentstehung, Tuberkulosebekämpfung und Säuglingsernahrung. Beitr Exper Therap. 1904;8:20-52.

15 Schlossmann A. Die Tuberkulose im frühen Kindesalter. Beitr Klinik Tuberk. 1906;6(3): 229-47.

16 Georg G, Ghon A. Münchener medizinische Wochenschrift. Dtsch Med Wochenschr. $1936 ; 83 ; 1569-70$.

17 Schulman ST, Friedmann HC, Sims RH. Theodor Escherich: the first pediatric infectious diseases physician? Clin Infect Dis. 2007;45: 1025-9.

18 Ghon A, Winternitz F. Zur frage über die Häufigkeit der primären pulmonalen und extrapulmonalen Tuberkuloseinfektion beim Säugling und Kind. Z Tuberk. 1924;39:40117.

19 Canti RG. Primary pulmonary tuberculosis in children. QJM. 1919;os-13(49):71-81.

20 Blumenberg W. Die Tuberkulose des Menschen in den verschiedenen Lebensaltern auf Grund anatomischer Untersuchungen I. Beitr Klin Tuberk. 1925;62(5):532-90.

21 Blacklock JWS. Tuberculous disease in children: its pathology and bacteriology. London: His Majesty's Stationary Office; 1932.

22 MacGregor AR, Alexander WA. Pulmonary tuberculosis in children. Edin Med J. 1937;44: 561-95.

23 Ghon A. Über kavernöse äuglingstuberkulose. Z Tuberk. 1925;43:3-14.

24 Ghon A. Über Sitz, Grösse und form des primären Lungenherdes bei der Säuglingsund Kindertuberkulose. Virchows Arch. 1925; $254: 734-50$

25 Zarfl M. Zur Kenntnis des primären tuberkulosen Lungenherdes. Z Kinderheilkd. 1912;5: 303-21.
26 Ghon A, Kudlich H. Die Eintrittspforten der infection vom Standpunkte der Pathologischen Anatomie. In: Engel ST, Pirquet CL, editors. Handbuch der Kindertuberkulose. Leipzig: Georg Thieme Verlag; 1930. p. $20-$ 113.

27 Ghon A, Pototschnig G. Über den Unterschied im pathologisch-anatomischen Bilde primärer Lungen- und primärer Darminfektion bei der Tuberkulose der Kinder. Beitr Klini Tuberk. 1919;40(1-2):87-109.

28 Pagel W, Price DS. Description of very early TB focus. Am Rev Tuberc. 1943;47:614-7.

29 Ranke KE. Primäraffekt, sekundäre und tertiäre Stadien der Lungentuberkulose. Dtsch Arch Klin Med. 1916;119:201-69.

30 Ghon A. Zur Frage der sogenannten endogenen Reinfektion bei der Tuberkulosekrankheit des Menschen. Z Ges Exp Med. 1926;50(1):26-33.

31 Ghon A, Pototschnig G. Über den primären tuberkulösen Lungenherd beim Erwachsenen nach initialer Kindheitsinfektion und nach initialer Spätinfektion und seine Beziehungen zur endogenen Reinfektion. Beitr Klinik Tuberk. 1919;41(1-2):103-23.

32 Ghon A, Kudlich H. Zur Reinfektion bei der menschlichen Tuberkulose. Z Tuberk. 1925, 41:1-17.

33 Ghon A, Kreider P, Kudlich H. Zur Entstehung der Reinfektion der menschlichen Lungenphthise. Virchows Arch Path Anat. 1927; 264(3):563-86.

34 Ghon A, Kudlich H, Schmiedel St. Zur Reinfection der Tuberkulose beim Menschen. Verh Dtsch Pathol Ges. 1926;12-4:328-32.

35 Ghon A, Kudlich H, Schmiedel St. Die Veränderungen der Lymphknoten in den Venenwinkeln bei Tuberkulose und ihre Bedeutung. Eine Studie zur Frage der Reinfektion. Z Tuberk. 1926;46:1-31.

36 Orth J. Über tuberkulöse Reinfektion und ihre Bedeutung für die Entstehung der Lungenschwindsucht. Sitzungsber d preuss Akad d Wiss III; 1913.

37 Cardona P-J. The key role of exudative lesions and their encapsulation: lessons learned from the pathology of human pulmonary tuberculosis. Front Microbiol. 2015;6:612.

38 Mayito J, Andia I, Belay M, Jolliffe DA, Kateete DP, Reece ST, et al. Anatomic and cellular niches for Mycobacterium tuberculosis in latent tuberculosis infection. J Infect Dis. 2019;219(5):685-94.

39 Ong CW, Elkington PT, Friedland JS. Tuberculosis, pulmonary cavitation, and matrix metalloproteinases. Am J Respir Crit Care Med. 2014;190(1):9-18.

40 Tezera LB, Mansour S, Elkington P. Reconsidering the optimal immune response to Mycobacterium tuberculosis. Am J Respir Crit Care Med. 2020;201(4):407-13.

41 Medlar EM. The pathogenesis of minimal pulmonary tuberculosis; a study of 1,225 necropsies in cases of sudden and unexpected death. Am Rev Tuberc. 1948;58(6):583611.
42 Hunter RL. Pathology of post-primary tuberculosis of the lung: an illustrated critical review. Tuberculosis. 2011;91:497-509.

43 Schmidek HH, Hardy MA. Pulmonary tuberculosis with normal chest radiographs: report of eight cases. Can Med Assoc J. 1967;97(4): 178-80.

44 Houk VH, Kent DC, Baker JH, Sorensen K, Hanzel GD. The Byrd study. In-depth analysis of a micro-outbreak of tuberculosis in a closed environment. Arch Environ Health. 1968;16(1):4-6.

45 Mulenga H, Moyo S, Workman L, Hawkridge T, Verver S, Tameris M, et al. Phenotypic variability in childhood TB: implications for diagnostic endpoints in tuberculosis vaccine trials. Vaccine. 2011;29(26):4316-21.

46 Loveday M, Sunkari B, Marais BJ, Master I, Brust JC. Dilemma of managing asymptomatic children referred with "culture-confirmed" drug-resistant tuberculosis. Arch Dis Child. 2016;101(7):608-13.

47 Robertson HE. The persistence of tuberculous infections. Am J Pathol. 1933;9(Suppl): 711-718.

48 Sweany HC. Studies on the pathogenesis of primary tuberculosis infections. 1. The regressive lesions. Am Rev Tuberc. 1933;27: 559-74.

49 Pagel W, Toussaint CH. Pathology of reinfection; some sources of diagnostic errors. Am Rev Tuberc. 1948;58(1):85-97.

50 Canetti G. Exogenous reinfection and pulmonary tuberculosis. A study of pathology. Tubercle. 1950;31:224-8.

51 Rich AR. Exogenous or endogenous reinfection? Is an arrested primary infection protective or deleterious? The pathogenesis of tuberculosis. 2nd ed. Springfield, Illinois: Charles C. Thomas; 1951. p. 790-822.

52 Nardell E, McInnis B, Thomas B, Weidhaas S. Exogenous reinfection with tuberculosis in a shelter for the homeless. N Engl J Med. 1986; 315(25):1570-5.

53 Marx FM, Dunbar R, Enarson DA, Williams BG, Warren RM, van der Spuy GD, et al. The temporal dynamics of relapse and reinfection tuberculosis after successful treatment: a retrospective cohort study. Clin Infect Dis. 2014; 58(12):1676-83.

54 Sutherland I, Svandová E, Radhakrishna S. The development of clinical tuberculosis following infection with tubercle bacilli. 1. A theoretical model for the development of clinical tuberculosis following infection, linking from data on the risk of tuberculous infection and the incidence of clinical tuberculosis in the Netherlands. Tubercle. 1982;63(4):255-68.

55 Vynnycky E, Fine PE. The natural history of tuberculosis: the implications of age-dependent risks of disease and the role of reinfection. Epidemiol Infect. 1997;119(2):183-201.

56 Ghesani N, Patrawalla A, Lardizabal A, Salgame P, Fennelly KP. Increased cellular activity in thoracic lymph nodes in early human latent tuberculosis infection. Am J Respir Crit Care Med. 2014;189(6):748-50. 
57 Esmail H, Lai RP, Lesosky M, Wilkinson KA, Graham CM, Coussens AK, et al. Characterization of progressive HIV-associated tuberculosis using 2-deoxy-2-[18F] fluoro-D-glucose positron emission and computed tomography. Nat Med. 2016;22(10):1090-3.

58 Geadas C, Acuna-Villaorduna C, Mercier G, Kleinman MB, Horsburgh CR, Ellner JJ, et al. FDG-PET/CT activity leads to the diagnosis of unsuspected TB: a retrospective study. BMC Res Notes. 2018;11:464.

59 Lida T, Uchida K, Lokman N, Furukawa A, Suzuki Y, Akashi T, et al. Calcified granulomatous lung lesions contain abundant $\mathrm{Myco-}$ bacterium tuberculosis components. J Mycobact Dis. 2014;4:1.
60 Keanne S, Ganchua C, Cadena AM, Maiello P, Gideon HP, Myers AJ, et al. Lymph nodes are sites of prolonged bacterial persistence during Mycobacterium tuberculosis infection in macaques. PLoS Pathog. 2018;14(11): e1007337.

61 Basaraba JR, Smith EE, Shanley CA, Orme IM. Pulmonary lymphatics are the primary sites of Mycobacterium tuberculosis infection in guinea pigs infected by aerosol. Infect Immun. 2006;74(9):5397-401.

62 Behr MA, Waters WR. Is tuberculosis a lymphatic disease with a pulmonary portal? Lancet Infect Dis. 2014:14:250-5.
63 Wolf AJ, Desvignes L, Linas B, Banaiee N, Tamura T, Takatsu K, et al. Initiation of the adaptive immune response to Mycobacterium tuberculosis depends on antigen production in the local lymph node, not the lungs. J Exp Med. 2008;205:105-15.

64 Davis JM, Ramakrishnan L. The role of the granuloma in expansion and dissemination of early tuberculous infection. Cell. 2009;136: 37-49.

65 Mathiasen VD, Hansen AK, Eiset AH, Lillebaek T, Wejse C. Delays in the diagnosis and treatment of tuberculous lymphadenitis in low-incidence countries: a systematic review. Respiration. 2019;97(6):576-84.

66 Koch R. Die aetiologie der tuberkulose. Mitt Kais Gesundheitsamte. 1884;11:467-565. 